\title{
Procedencia clasicista de los colectores de refranes castellanos
}

\author{
FERMÍN DEL PINO DÍAZ \\ Dpto. de Antropología de España y América
}

CSIC. Madrid

\section{RESUMEN}

Se examinan brevemente las obras principales escritas en los siglos XV, XVI y XVII sobre refranes españoles, así como la bibliografía reciente sobre ellas. Se ponderan las teorías explicativas sobre su temprano y masivo desarrollo en España, proponiéndose aquellas que enfatizan el papel de modelo ejercido por la paremiología clásica, ligada al erasmismo, conectando este fenómeno con los fundamentos cosmopolitas de la antropología moderna.

Palabras clave: Refranes españoles, Colecciones de refranes, Renacimiento, Antropología.

\section{SUMMARY}

The author reviews the main works on Spanish wise sayings written in the $15^{\text {th }}, 16^{\text {th }}$ and $17^{\text {th }}$ centuries as well as the recent literature about these works. After pondering the different theories received with regard to their early and extensive development in Spain, he favors those that point to the model of Classical paremiology, obtained through Erasmism - an intellectual tradition which he relates to the cosmopolitan foundations of modern anthropology.

Key words: Spanish Wise Sayings, Collections of Wise Sayings, Renaissance, Anthropology.

RDTP, LVII, 2 (2002): 203-224 
Casi todas las 'invenciones' antropológicas ban tenido carácter cosmopolita.

(Del Pino 1992: 119)

\section{PRELIMINARES ${ }^{1}$}

Obedeció la elección temática del curso de postgrado del año 1999, en parte, a la poderosa personalidad de don Julio Caro Baroja, cuyo nombre llevan estos cursos, porque él mostró un gran interés por la historia internacional del pensamiento antropológico y, en particular, del nacional "conocimiento de sín: justamente las dos coordenadas que se pretendieron conectar en el caso histórico ofrecido a estudio en el curso. En su historización nacional de la disciplina, aunque parezca paradójico, enfatizó Caro la importancia histórica de filósofos greco-romanos y de alemanes como Kant o Herder, mucho más que la de los viajeros españoles de los siglos XVII-XVIII o de los misioneros del Renacimiento.

Don Julio era un tipo humano muy hispano, como mostró en su personalísimo modo de vida o incluso en sus frecuentes y originales biografías, que tanto se beneficiaron del estilo literario y artístico acuñado dentro de la familia Baroja; pero al mismo tiempo era muy erudito y muy internacional, aunque fuese a veces a costa de usar sus propias relaciones familiares y de amistades. Tal vez se deba el amplio consenso nacional que logró su obra en la academia española - que no importa para ello sólo el ámbito universitario oficial, de donde estuvo escandalosamente ausente- justamente a la mezcla de las virtudes propias del sabio del mundo antiguo, con la sinceridad y gracia del ciudadano perspicaz. Don Julio dedicó lo principal de su tiempo a los libros antiguos y a las ricas muestras del variado paisaje étnico hispano - en trance de extinción, y

\footnotetext{
${ }^{1}$ Durante el mes de marzo de 1999 organicé el XIX Curso de Etnología Española "Julio Caro Baroja", que se tituló La construcción nacional de la Antropología. El factor foráneo. Se dedicaron 10 conferencias, comenzando por ésta mía, a revalorizar el peso de antropólogos o de movimientos extranjeros en el desarrollo profesional de la antropología nacional, poniendo el acento en el período contemporáneo: debates ilustrados sobre la cultura y literatura nacional; viajeros románticos por España; escuela de Costa y de los hermanos Menéndez Pidal; evolucionistas y difusionistas españoles; escuela catalana de psicología étnica; visita de antropólogos extranjeros a Castilla, y la obra hispana de Pitt-Rivers. A pesar del interés de los temas y los conferenciantes, no me ha sido posible en el plazo transcurrido incluir otros manuscritos que los dos que aquí se presentan en forma aislada (Cf. trabajos de N. ORTEGa y L. Calvo). En los preliminares de este artículo se explican someramente las coordenadas conceptuales del curso.
} 
en aguda crítica por ello-, pero no dejó de escribir en los periódicos acerca de la bulliciosa vida hispana y vasca, no eludiendo la polémica enconada, sino todo lo contrario.

Sin pretenderlo, heredó mucho de otro sabio vasco, Unamuno, amigo personal en su juventud y pariente de su maestro Aranzadi, que sabía combinar la exaltación de la callada y escondida intrabistoria hispana con la palpitante actuación del famoso repúblico, de cuyos escritos diarios pendía el país. Don Julio procedía también originariamente del campo de la historia antigua y siempre manejó a los clásicos greco-romanos con la familiaridad del iniciado. Fueron ellos los que le inspiraron su concepción de la España antigua y tradicional, comenzando por el mundo vasco y el matriarcado, tema de su tesis doctoral. Conservó toda su vida una lealtad hacia los clásicos, utilizándolos al principio para sus detallados informes etnohistóricos, y luego defendiendo su valor intelectual, tanto en la protohistoria de nuestra disciplina, como en la oferta de nuevos y desacralizados modelos de vida ${ }^{2}$.

Pero el presente curso no se hizo para su homenaje. Como es sabido, me ha interesado ha tiempo la historia de la antropología española, pero no he restringido mi atención al conocimiento del propio universo nacional sino a la inversa, abriéndome especialmente a su actuación en el extranjero (América, África, Oceanía). Eso se debe en parte, tal vez, a mi primitiva dedicación a los estudios americanos, desde mi licenciatura originaria en Ciencias Políticas. Pero también a la coyuntura nacional particular de los estudios antropológicos en España, muy influidos por la acción hispana en el exterior: en su mayor parte se renovaron por influencia americanista. Recuérdese el carácter desencadenante para la profesión antropológica española actual de la escuela de Claudio Esteva en Madrid y Barcelona, y de diferentes exilados políticos, casi todos en América (Bosch-Gimpera, Barandiarán, Palerm, Carrasco, Armillas, etc.), así como la importancia, precursora para la antropología universitaria, de los departamentos americanistas de Madrid, y especialmente de Sevilla y Barcelona ${ }^{3}$.

Mi dedicación a la subdisciplina "historia de la antropología" fue determinada tal vez también por mi dedicación americanista, tratando de probar un hecho que me parecía evidente y admitido a medias en el

\footnotetext{
${ }^{2}$ He desarrollado este punto de vista biográfico-intelectual en el homenaje que le dedicó la RDTP, en 1996.

${ }^{3}$ He desarrollado más este argumento en mi artículo de 1992, que forma una parte pequeña de un debate mayor. Todo el número monográfico de esa revista puede ser de gran interés para este problema de "las antropologías de España" y en él participaron un elenco representativo de los profesionales españoles, lo que explica su repercusión posterior.
} 
gremio internacional (la participación española temprana en el conocimiento etnográfico del Nuevo Mundo). Pero, de paso, me interesaron en sí mismas sus consecuencias en la historia profesional posterior y la metodología particular como tal estudio histórico-científico. Mi interés histórico genuino evitó caer en el "precursismo" tradicional de las historias nacionalistas, siendo muy consciente de ese contexto nacional, así como del paradójico valor gremial de un trabajo historiográfico bien hecho para la consolidación profesional de la disciplina.

Mi interés histórico se resistió deliberadamente al "presentismo" gremial y nacionalista, ante todo por la denuncia sistemática del maestro americano George W. Stocking, pero no dejaba de observar por mi cuenta la interna conexión meta-disciplinar entre el pasado y el presente a través de unos textos sobrevivientes. Interpretar los textos exige una cierta capacidad de actualizar el pasado, de modernizarlo, tanto como de adaptarse a él. Actualmente me intereso más en estudiar y editar críticamente -i.e., interviniéndolos - textos concretos -eso sí, que me parezcan fundacionales para la etnohistoria hispano/americana- que no en valorar positivamente sus contenidos desde la historia de la ciencia. Frente al interés contextual o puramente intelectual de gran parte de mis colegas historiadores de la disciplina, y de mi propia tesis doctoral, en parte derivado del entusiasmo del 68 , conservé luego mi interés predominante por los textos.

Mi traslado en 1993 del Instituto de Historia del CSIC al Instituto de Filología - y más recientemente al Instituto de la Lengua Española- ha coincidido con una búsqueda personal de "coherencia" interdisciplinar, y de curiosidad literaria y filológica, por las cuales insisto ahora menos en hacer antropólogos a los autores -que no pertenecieron stricto sensu a un contexto disciplinar antropológico- y más en practicar yo un "punto de vista" antropológico. Es decir, dejar hablar a los autores y esforzarme más en comprenderlos, que no en "defenderlos" como científicos usándolos more militari para mi causa disciplinar. Creo que ello se debe seguramente, tanto a la benéfica influencia de Stocking, cuyo magisterio metodológico sigo desde 1975, como a la anterior tradición "historicista" de mis maestros Díez del Corral y Maravall, en los primeros años de la década de 1960. Tal vez corría realmente un hilo de familia entre los dos ambientes, no tan alejados como pudiera parecer.

Estoy convencido del peligro provinciano que asalta a todo "historiador de sí mismo". Bien claro me quedó hace tiempo — del repaso bibliográfico sobre los manuales de historia de la antropología que tuve que hacer como parte de mi tesis doctoral (1975) - que cada historiador de un oficio valora el pasado desde su presente, como acusaba Stocking en 
general a los antropólogos que historiaban la disciplina. Creo, no obstante, que una historia bien realizada (textualizada y contextualizada) puede devolver "vida propia" al pasado. Es lo que intentábamos en este curso de postgrado, invitando a una serie de especialistas para que nos ayudasen a considerar varios períodos y personajes de la historia antropológica española. El contexto que buscamos es justamente la coordenada "foránea", es decir el contexto internacional.

\section{EL FACTOR FORÁNEO DE LA TRADICIÓN ANTROPOLÓGICA}

La antropología ha sido más bien un conocimiento de la sociedad de los otros, no de la de sí mismo. El profesional habitual suele ocuparse de sociedades diferentes, lejanas o cercanas, y eso vale incluso para los más renuentes folkloristas. El propio Peter Burke (1991: 50) prestigioso especialista de la historia del propio conocimiento popular en Europa, reconoce que los grandes folkloristas del período contemporáneo se interesaron por las sociedades periféricas (Herder por las costumbres lituanas, Grimm por las hispanas, etc.), antes que por la propia del entorno aldeano alemán (la cual era también periférica al ámbito urbano del estudioso), y que este movimiento romántico vino precedido históricamente por un interés ilustrado por las costumbres y usos de pueblos de otros continentes. Incluso Kant era lector asiduo de libros de viaje alrededor del mundo -si bien tuvo opiniones sumarias y rigurosas sobre los salvajes-, como lo fueron anteriormente Locke (que prologó un libro de viajes) o el propio Leibniz (que dirigió la rica biblioteca de Wolfenbüttel — precedente directo de la British Library-, llena de libros de viaje). Naturalmente, no tenemos nada que añadir de otros ilustrados como Diderot o Turgot, Smith o Robertson, y Jovellanos o Muñoz. Michèle Duchet probó ya abundantemente en su difundida monografía sobre el Siglo francés de las Luces que los filósofos leían apasionadamente a misioneros y viajeros.

Este interés por el mundo "ajeno" es lo que caracteriza al mundo moderno, al que pertenece esencialmente la antropología. Sólo excepcionalmente se interesó por ello el mundo antiguo, aunque hubo unos pocos casos dignos de mención (Heródoto por los persas y escitas, Tácito por los germanos). Arnaldo Momigliano ha demostrado que Heródoto no era creído por los griegos, que veían exageradas sus alabanzas de persas y escitas, y usaban para su argumentación casuística solamente las ridículas descripciones de hombres monstruosos: desconocidos habitantes de los confines, que también incluía Heródoto, con alguna credulidad en las narraciones populares lejanas. Ni Tácito en la antigüedad romana ni Mar- 
co Polo en el mundo medieval europeo obtuvieron otro estatuto mejor de credibilidad que Heródoto, pues sus narraciones sobre germanos o sobre mongoles y chinos pasaron por ser libros "maravillosos", que no estaban obligados a creer como relatos fidedignos. La única sabiduría posible era la cristiana y los gentiles no tenían propiamente la posibilidad de alcanzarla, pues solamente la demorada revelación divina habría podido desembarazarlos de las sombras del paganismo y el politeísmo.

No otro es el "estado de la cuestión" a partir de los trabajos de John H. Rowe (1965) —un respetado arqueólogo incaísta, ahora tristemente retirado de la vida de su claustro de Berkeley-, basado en Momigliano y en Panofsky, entendidos en la ciencia antigua y medieval. Esta "sabiduría exótica" o de los otros, pues, sería colectiva y verdaderamente apreciada solamente en el mundo moderno, que se educó en el contacto directo con los clásicos, paradójicamente. La paradoja es que quienes vivían cerca del pasado clásico (todo el mundo medieval) no lo apreciaban verdaderamente en sí mismo, sino por sus concomitancias con el mundo cristiano, y hubo que considerar a los sabios greco-romanos como definitivamente "perdidos" para que fuesen totalmente reconocidos por los cristianos. Esta tradición etnocéntrica cristiana, que consideraba sin interés a los bárbaros, procedía en realidad del mundo clásico y la denunció el paremiólogo humanista sevillano Juan de Mal Lara en el primero de sus preámbulos a la famosa Philosophia vulgar (Sevilla, 1568):

En fin no huvo nación tan bárbara [...] que no pudiesse hazer catálogo de los que entre sí havían professado (si no letras) algún saber, que le quedasse como herencia espiritual. Y los que más se jactaron deste bien, y se gloriaron deste nombre, y quisieron ganarla a los otros fueron los griegos, que a todos llamaron bárbaros, y levantaron pendones por la sabiduría en nombre de los siete Sabios [...] Y viniendo a tanta presunción, se atribuyeron con estudio (por ventura aprendido de bárbaros), el nombre admirable de sabios, que su lengua decía sophís [...] no faltó alguno que se enfadasse del nombre impuesto en hombres que tanto les faltava para henchir la medida de tan glorioso título. Y fue Pithágoras éste, que haviendo aprendido mucho, caminando y navegando por diversas tierras, llegando al mercado destos sabios [...] les hizo conocer [...] y púsole el nombre de Philosophia, que es desseo de saber (1996: 28) ${ }^{4}$.

${ }^{4}$ Subrayamos siempre nosotros, y no con cursiva, para diferenciarnos de los énfasis del autor citado. El subrayado presente quiere llamar la atención, sobre el interés de la idea, casi emblemática y aforística, de que creer en la barbarie es de bárbaros. Como diría Levi-Strauss, remedando seguramente a Montaigne en su trabajo sobre "Racismo e historia": "Le barbare c'est d'abord celui qui croit à la barbarie". No está mal de parte del humanista andaluz, que alguien ilustre en nuestra historiografía cultural, como Américo Castro, llamó de segunda fila. También los rankings de valor son relativos, no solamente los valores de una cultura respecto a otra. 
Hasta que los italianos del siglo XIV no sintieron la necesidad de "recuperar" esa cultura clásica —olvidada por la corte papal trasladada a Avignon, que ya patrocinaba el gótico y no el románico, y que empezaba a cultivar la poesía provenzal y no el latín-, no se rescataron con exhaustividad los numerosos códices y monumentos conservados de la Antigüedad a lo largo del Mediterráneo (Cicerón y Virgilio, particularmente, así como los venerados textos griegos, llegados ahora directamente de los letrados huidos de Constantinopla en el siglo xv, y ya no a través de los árabes). Con el rescate de los textos y monumentos originales (en manuscritos celosamente cuidados y copiados en monasterios retirados, ahora críticamente reconstruidos) vino la nueva consciencia de que esos ancestros eran diferentes de nosotros, sus herederos cristianos y, sin embargo, dignos de estudio y modelos de vida y pensamiento. Es entonces también cuando sus textos sobre otros pueblos y culturas de la Antigüedad, aún no creídos, comienzan a tomarse en serio y cuando se incorporan nuevos pueblos de la periferia europea como igualmente dignos de estudio, descripción y admiración.

Los cristianos comienzan no solamente a estudiar los textos antiguos y a describir con minuciosidad los pueblos nuevos, sino que esas culturas devienen motivo de admiración y de una simultánea crítica interna de parte del propio cristianismo. La Utopía de Tomás Moro -íntimo de Erasmo y colaborador en la empresa de cristianizar a los clásicos- consiste en una contraposición entre la ejemplar sobriedad y justicia de una sociedad nuevamente aparecida del otro lado del océano - pero cuya descripción se atiene a patrones idealizados a partir del mito clásico de la Edad de Oro, más que a las noticias reales que comienzan a llegar del Nuevo Mundo-, frente a la corrupción y rigor extremo de la cristiana sociedad inglesa: ésta contempla impotente la existencia de ladrones por causa del hambre y mal reparto de riquezas, que son "cristianamente" tratados con la cruenta amputación de sus manos.

Pero la nueva curiosidad y ejemplaridad por el mundo antiguo se aplica no solamente a los hombres del pasado, o a los pueblos nuevos -el Nuevo Mundo, que tanto contribuyeron a descubrir y a describir los patrones clásicos de ciencia e historia- sino a la propia periferia social. La curiosidad por la periferia temporal facilitó la curiosidad por la propia periferia espacial. Los campesinos mismos o los pastores serán tratados pronto como ejemplos de un mundo pasado todavía superviviente, del que nos hablaban las fuentes antiguas - recuérdese la famosa imagen de la Edad de Oro, que don Quijote halla en los pastores manchegos-, como ya se aplicó pronto al mundo lejano nuevamente descubierto, del que nos hablan entusiasmados los afortunados viajeros. 
Además de esta naturaleza periférica habitual en el contenido de la antropología, y posiblemente por alguna razón de coherencia interna, hay un componente periférico también en el surgimiento de la propia disciplina, en la composición social de sus miembros. La antropología británi$\mathrm{ca}$, por ejemplo, es inexplicable sin el polaco Malinowski, la norteamericana sin el judío prusiano Franz Boas y la francesa sin dos judíos de Estrasburgo como Durkheim y su sobrino M. Mauss - franceses, pero nacidos en la región fronteriza con Alemania, la zona del Ruhr-. Estos extranjeros se trasladaron a las capitales de los respectivos imperios e impusieron un enfoque cosmopolita y renovador a sus estudios, que desencadenaron posteriormente discípulos del propio país, y un interés novedoso por el mundo propio.

Lo mismo puede decirse que ha ocurrido entre nosotros. La antropología que ahora practicamos nacionalmente, o incluso "autónomamente" en cada región o nacionalidad española, parece que ha surgido de nosotros mismos: justamente porque centramos a corto plazo la atención en nosotros, como más cercanos. El objeto nacional o regional tiende a confundirse genéticamente por la comunidad de estudiosos - al hacer memoria de sí mismos- con su punto de vista disciplinar, con el gremio que lo cultiva, pero no es así. En esta asociación de cosas ocurre algo parecido a la asociación de nombres con que distinguimos, bajo el término "folklore", tanto a la disciplina misma como a su objeto de estudio. El propio don Julio (que nos parece tan autónomo en España, tan Baroja) se formó primero con profesores alemanes como Trimborn - como su maestro Aranzadi había bebido también en fuentes alemanas-, y luego aún completó su formación con anglosajones como Foster o Pitt-Rivers, que le llevaron una larga temporada a su propio país. Junto a don Julio, han dejado abundantes discípulos españoles, profesores como Carmelo Lisón y Claudio Esteva, formados ya directamente en el extranjero. Como hemos dicho al principio, los departamentos americanistas gestaron en la universidad española la materia antropológica, pero ellos mismos han estado originariamente dirigidos por profesores formados en Alemania u otros países europeos (A. Castro, R. Altamira, P. Bosch-Gimpera o M. Ballesteros). Ni que decir tiene que la formación cosmopolita es ley general, porque los sabios extranjeros también necesitan del contacto exterior como de la leche materna.

Pero yo me pregunto si esto es un fenómeno sólo reciente en España o lleva más tiempo. A esa pregunta trataba de responder este curso, que se remontó al Renacimiento, la Ilustración y el Romanticismo, antes de ocuparse de figuras contemporáneas como Joaquín Costa o los hermanos Menéndez Pidal, o incluso de los profesores extranjeros más hodiernos 
que han impulsado la antropología nacional o regional española actual (Pitt-Rivers, Foster, Brandes, Kenny, Arguedas...).

3. COSMOPOLITISMO RENACENTISTA Y DESCUBRIMIENTO DEL PROPIO PUEBLO. LOS NOMBRES PRINCIPALES

Es habitual referirse al Renacimiento como comienzo de un interés por el mundo exótico, pero también se desarrolló entonces una primera curiosidad por el mundo periférico propio, que no suele reconocerse tanto. Como vimos, Peter Burke mencionaba la influencia fundacional de esta tradición "anticuaria" y exoticista del Romanticismo por otros pueblos, como parte del proceso de descubrimiento de la "cultura popular", pero no admite todavía un interés folklórico de parte del Renacimiento, el interés por la propia cultura popular. Es el punto que nos gustaría desarrollar un poco, reconociendo que es un problema "abierto" - sujeto a debate- que espera una respuesta matizada, apropiada a su complejidad. Por el momento, nos gustaría referirnos al "estado de la cuestión" sobre el tema, sin afán alguno de exhaustividad pero dispuestos a ofrecer materia para una reflexión nueva.

La selección prioritaria de la paremiología obedece a que posiblemente sea el caso más estudiado hasta el momento, en el campo amplio del folklore hispano, y, aunque sea un caso que queda relativamente lejos de mi personal investigación historiográfica, tal vez nos puede beneficiar mucho el debate abierto acerca de su cultivo por el sector clasicista.

No nos mueve primariamente un afán apologético y patriótico, como dijimos al principio - sabiendo de antemano el defecto "presentista" que suelen tener estos planteamientos histórico/científicos-, sino más bien la pretensión de establecer conexiones generales - no sólo hispanas- entre diversos fenómenos histórico-científicos. Tomaremos los datos directamente de los iniciales reivindicadores de sus méritos folklóricos a comienzos o mediados del s. XX, como predecesores de los estudios presentes, o de simples historiadores (de gentes como Menéndez Pelayo o Américo Castro, Guichot o Navascués, o incluso de Bataillon o Maravall). Es posible que puedan parecer unas guías demasiado alejadas o arcaicas, pero en realidad no es así, como queremos probar. Al revés, debemos hoy manifestar nuestro reconocimiento a sus propias intuiciones. A pesar de su contexto coyuntural particular, e incluso dentro de una cierta "polémica de la ciencia española", dieron en la clave de una concatenación particular de fenómenos (entre el clasicismo de procedencia disciplinar y el 
vulgarismo folklórico de su interés), que luego me ha parecido oscurecida $-\mathrm{O}$ incluso olvidada - en los estudiosos presentes.

No tratamos en esta ocasión de descubrir datos nuevos, ni siquiera de centrarnos monográficamente en algún caso particular, y por ello no creemos necesaria una puntualización bibliográfica minuciosa (véase para iniciarse parcialmente la parte $\mathrm{B}$ de nuestro epígrafe final). Tiempo habrá en otra ocasión más específica de hacer precisiones que nos han salido al paso (peso folklórico del erasmismo, contexto nacionalista temprano, protagonismo andaluz, comparación internacional de humanismos, etc.). Los personajes y obras normalmente mencionados a este respecto serán el Marqués de Santillana (1508) ${ }^{5}$, Juan de Valdés (Roma, 1534-36), Blasco de Garay (Toledo, 1541), Pedro Vallés (Zaragoza, 1549), Sebastián de Orozco (Toledo, c. 1550), Hernán Núñez "el Comendador Griego" (Salamanca, 1555), Lorenzo Palmireno (Zaragoza, 1560), Juan de Mal Lara (Sevilla, 1568), Sebastián de Cobarruvias (Madrid, 1611), y finalmente Gonzalo Correas (de 1627, pero inédito hasta Madrid, 1906) ${ }^{6}$.

Creo que los dos más importantes son el maestro Correas y el maestro Mal Lara: el primero por la cantidad de su colección y el segundo por la calidad de sus glosas explicativas, así como por su estudio preliminar, o "preámbulos". Parece que Hernán Núñez debió muchos de sus refranes (3.000) al humanista Juan Páez de Castro, según confesaba éste a su amigo el historiador aragonés Jerónimo de Zurita en una carta de 14XII- $1545^{7}$, y parece que compraba y que no terminó de glosarlos, cuando

\footnotetext{
${ }^{5}$ Con muchas ediciones en Sevilla (en 1508, 1512, 1515, 1516, 1522, 1542, 1608), junto con las anteriores del Centiloquio de sus Proverbios y Castigos, glosados por él y Pero Díaz de Toledo, traductor a su vez de unos proverbios de Séneca, poco anteriores y también con muchas ediciones sevillanas. Confusión supuesta entre ambas obras de parte de Mal Lara, acusada en Morel-Fatio (1911), su editor, y aún padecida sorprendentemente por Bataillon (1937-1979: 51, nota 32).

${ }^{6}$ Como guía general introductoria sobre el mundo de la paremiología, puede valer bien el breve trabajo de $\mathrm{H}$. Velasco (1981), interesado en una visión antropológica moderna de actualidad, pero hemos encontrado particularmente útil para el período renacentista el breve artículo de Hayes (1937) y el de Berkowitz (1925) por su sistemática. Mucho más tentativos son los manuales al uso de Guichot (1922) y de Navascués (1931), que deben historiar todas las etapas del folklore, no sólo la renacentista, y que mezclan lo literario y lo folklórico en su afán de incluir todo lo que pueda tener valor. Naturalmente son útiles los catálogos de Sbarbi (1874) y García Moreno (1918), aunque no se reducen al período renacentista.

7 (Apud Bataillon 1979: 626). La carta fue publicada varias veces: entre la correspondencia de Zurita, por el propio Sbarbi, por el editor del Comendador y recientemente entre la correspondencia general del Comendador Griego, donde se prueba su interés final por reunir refranes, entre 1539 y 1547. Cf. Signes Codoñer et al. (2001).
} 
los dio a imprimir, aunque es importante el impacto posterior sobre su discípulo Mal Lara, y sobre la tradición salmantina.

No mencionamos otras obras donde se usaron reiteradamente los refranes, como la Celestina o el Quijote, así como tampoco otros muchos tratados paremiológicos del XVII, porque no nos valen para la discusión que proponemos: no son propiamente tratados, o no son del período. Nos vamos a ceñir en realidad a una consideración genérica de los mismos, con breves menciones particulares cuando se trate de un punto de relevancia general. Los casos más pertinentes a la discusión son siete: los Proverbios y los Refranes glosados del marqués de Santillana, El diálogo de la lengua de Juan de Valdés, los Proverbios en refranes del catedrático Hernán Núñez, la Philosophía vulgar del maestro Mal Lara y los vocabularios glosados de Horozco, de su hijo Cobarruvias y del catedrático Correas. Creo que, aunque se trate precisamente de los más relevantes humanistas, son precisamente los casos más interesantes desde el punto de vista del folklore y de la paremiología. Son ellos quienes reunieron más refranes, los que se editaron con más asiduidad (especialmente Santillana, Nuñez y Mal Lara, a veces conjuntamente), y los que pretendieron darle más importancia en sus textos al significado y la glosa de los mismos.

Con todos ellos hay algún problema y sería conveniente realizar nuevos y prolongados estudios. Del marqués de Santillana se ha llegado a dudar de la paternidad sobre los refranes, sin acabar todavía de resolver la cuestión; Núñez y Mal Lara no publicaron todo lo que tenían preparado (uno por empezar a hacerlo en la vejez y otro por su muerte prematura), aunque son probablemente los más estudiados; Horozco, Valdés y Correas permanecieron inéditos mucho tiempo, aunque sus obras tardías son posiblemente las más completas. Algunos autores no nos dejaron bien conservado e identificado el resultado de sus estudios, como el famoso Páez de Castro. El volumen de refranes reunidos fue aumentando progresivamente (desde los 728 del marqués hasta los 25.000 de Correas). De todos ellos, la obra cumbre es, sin duda la del sevillano Mal Lara, aunque sus 1.000 refranes conservados y glosados no es sino la décima parte de lo que preparaba: sin embargo, su énfasis en la glosa y en la fidelidad de la colecta le acerca más que a nadie a nuestros intereses folklóricos, como se dijo hace tiempo por Marcelino Menéndez y Pelayo, en dos o tres ocasiones en que se refirió de pasada a ella.

Nosotros lo citamos, a pesar de no conocerse esta colección de Páez, por el significado relevante de su figura dentro del humanismo europeo, necesitado urgentemente de un estudio adecuado a su relieve. El propio Arias Montano habría reunido refranes, pues dejó, según Mayans, «en la biblioteca del Escorial unos apuntamientos de refranes" (Sbarbi, 1891, p. 321a). 
Trataremos los problemas más importantes de cada uno, para intentar comentar de un modo mínimamente sistemático lo que les une en lo que respecta a su interés folklórico y antropológico. De Santillana persiste todavía hoy la duda de su paternidad, precisamente desde 1911 en que el profesor Foulché lo cuestionaba por sus gustos aristocráticos, educados en el Renacimiento italiano. Tal duda fue rechazada por Berkowitz (1925) y por Sánchez y Escribano (1942), en base a los argumentos de Américo Castro sobre el populismo del Renacimiento, y ha sido igualmente rechazada por R. Lapesa en su estudio magistral sobre Santillana, aunque dude aún de que su colección implique aprecio de la filosofía vulgar:

El rey don Juan pudo gustar de este manojuelo de sentencias vulgares y contrastarlo con los doctos proverbios elaborados por el Marqués. Pero tanto el monarca como el vasallo que los recogió los mirarían como juguete, divirtiéndose con su plasticidad expresiva o con la malicia socarrona de su intención. Lo que seguramente no hicieron fue estimarlos como tesoro de sabiduría, como condensación de secular experiencia humana. Para esto hacía falta que pasasen bastantes años, durante los cuales la colección se divulgaría poco. Pero hacia 1500 el gusto por lo popular triunfaba en la corte y en la literatura, eran los días de Encina, el Cancionero musical y Fernando de Rojas (1957: 262).

Creo que no hay base para que Bataillon diga en nota en la nueva versión castellana de su Erasmo y España, restaurando las antiguas dudas de Foulché:

La atribución (tardía) de estos Refranes al Marqués de Santillana no parece ya, en 1964 ni segura ni significativa de los gustos del Marqués. Cf. R. Lapesa.... La atribución pudo haber sido imaginada pensando en los Proverbios, o Centiloquio, obra de poesía gnómica, cuyo autor es ciertamente Santillana (1979: 51, nota 32).

Lo curioso es que él mismo confunde ambas obras de Santillana, dando en la nota 32 unos pies de imprenta equivocados (haciendo salir los refranes en Sevilla, 1494, etc., justo en las fechas de los Proverbios). Tal vez un cambalache involuntario de fechas y fichas, pero no lo es esa duda de atribución. Ocurre que la atribución de estos refranes a tamaño personaje pone en riesgo su explicación de la paremiología española como derivada de Erasmo, lo cual es denunciado por el profesor Maravall, poco después, pero dirigiendo la crítica al verdadero autor de la tesis sobre el origen erasmiano de la paremiología española, Américo Castro:

[...] lo que no advierte Castro es que en el siglo Xvi ese fondo 'popular' aparece ya teñido por un carácter protonacional que rápidamente adquiere una gran fuerza [...] Y de ahí que la exposición del problema que hace Castro [...] adolezca del error de perspectiva de referir toda la cuestión de los refranes, planteada en 
nuestro Renacimiento, a Erasmo y el erasmismo [...] nuestros humanistas no dejaron de darse cuenta de la importante diferencia que había entre los adagios que Erasmo recopiló y anotó y aquellos proverbios de que tantos escritores españoles se ocuparon [...] desde fechas, incluso, en las cuales la influencia erasmiana no podía darse, porque los Adagia [París, 1500] no habían sido todavía publicados. Hagamos resaltar una vez más, porque en ese matiz está tal vez lo más significativo del caso, que tal interés [por los refranes populares] no se descubre en escritores de tendencia castiza, apartados de la corriente general europea del Renacimiento [... sino] en los paladines del italianismo y del clasicismo [Santillana, Juan de Valdés, Hernán Nuñez, mosen Pedro Vallés, Juan de Mal Lara, el maestro León de Castro, el maestro Gonzalo Correas, etc., etc.]. (Maravall 1966: 408).

Efectivamente Américo Castro, en dos estudios trascendentes publicados en 1925 en el Centro de Estudios Históricos (dedicados a Cervantes y a Mal Lara, ambos en homenaje a su maestro R. Menéndez Pidal), había señalado la íntima conexión de estas paremiologías hispanas con el Renacimiento, y de éste con la reconocida influencia de Erasmo:

El refrán nos lleva al centro de la ideología renacentista. No sin misterio es aquella época la de las grandes colecciones de proverbios, y es en verdad muy significativo que varones tan doctos como Hernán Núñez, Mal Lara y otros se dediquen a reunir refranes. La clave de ello nos la da Erasmo, base, con sus Adagia, de los grandes refraneros [...] El refrán es la expresión del fondo de verdad, eterno y universal que la naturaleza buena puso en el hombre. Lo popular adquiere así un sentido nuevo merced al racionalismo humanista [...] De esta suerte se llega a la dignificación de lo popular en una época que desprecia soberanamente al vulgo, como incapaz de juicio y razonar propio [...] De todos modos, en España, por el sesgo especial de nuestra historia, el humanismo pone fuerte acento en esta rehabilitación del espíritu vulgar (1925a: 191-194)

Esta interpretación erasmiana ha pesado enormemente sobre la historiografía paremiológica, en particular la dedicada a Mal Lara (Sánchez y Escribano, A. Vilanova, M. Bernal...). Yo creo con Maravall que la interpretación del humanismo español a través del crisol de Erasmo empobrece su interpretación genuina, como ya denunció E. Asensio (1952) que la historia de la espiritualidad española a través del mismo crisol no agota su variedad real (dejando fuera no solamente la obra de San Juan de Ávila y los jesuitas sino de otras corrientes coincidentes).

\section{El Caso andaluz de Mal Lara}

No es el momento de señalar cualidades de Mal Lara que mal encajan en el erasmismo, sin necesidad de acudir a sus defectos (no originalidad ni grandeza, mediatización por la Contrarreforma), como hace Castro. Pero, 
puesto que Mal Lara es el paremiólogo más destacado, digamos algo de su caso. Su nacionalismo sevillano e hispano, su crédito a las tesis del dominico Annio de Viterbo sobre la venida privilegiada a España de Túbal y otros descendientes de Noé, su entusiasmo con las entradas reales en Sevilla, y con el apoyo real contra los turcos, su afición a los emblemas como materia filosófica per se, su interés directo en la paremiología popular y andaluza (por no seguir la lista de matices diferenciadores), nada tienen que ver directamente con el maestro de Rotterdam. Si bien es verdad que los humanistas norteuropeos habían estado también influidos por Italia, el caso particular de Erasmo y su experiencia monástica frustrada (así como su obsesiva dedicación libresca, como compensación de un cuerpo enfermizo) había provocado una distancia con otros humanistas, en particular con los hispanos, más interesados en disputar a Italia sus glorias históricas que en criticar a los frailes o a la iglesia de Roma aún corrupta ${ }^{8}$. Es verdad que Mal Lara evitaba los refranes anticlericales y que el nombre de Erasmo aparece tachado sospechosamente de la bibliografía en la Philosophia vulgar, pero eso no significa que el autor quisiese disimular un modelo; en el último de los preámbulos aparece específicamente citado como tal y se defiende:

Es una loable costumbre, en todo lo que glosamos o escrevimos, declarar los autores con que nos aprovechamos para abrir el camino a los que van leyendo, y mostrarnos agradescidos a quien tan bien nos ayuda [...] Ay otro mal de los que leen, que luego dizen ser todo trasladado y tomado, como que estos Preámbulos sean trasladados de los de Erasmo, y los refranes que van a la letra. Sería bien que el que lo dize, tomasse los libros y los cotejasse, y viesse quánto es trasladado, porque hurtado no se puede llamar lo que cuesta trabajo de passar de una lengua a otra, y deso, en algunos refranes doy larga cuenta. Procuré, pues, para este negocio, ver gran diversidad de autores griegos, latinos, castellanos y aun toscanos, si tenian algo que ayudasse a la declaración destos refranes [...] Sirve todo lo que he estudiado en treinta años para esta glosa [...] (Edición de 1996: 54).

No hace falta dar muchos más detalles de estos Preámbulos para saber que, si bien su autor sigue el modelo de Erasmo prologando sus Adagia (versión ampliada de Venecia, 1508) -incluso en el mero número de 14-, hay profundas diferencias de orden, estilo, énfasis, etc. Aunque sólo sea porque Erasmo argumentaba en favor de la sabiduría de los refranes antiguos (de Grecia, Roma, La Biblia, etc.) y Mal Lara de los presentes castellanos, algunos tomados directamente por él y preguntando a

\footnotetext{
${ }^{8}$ Interesante re-examen del humanismo de Erasmo en James D. Tracy (1980), señalando el matiz de que Erasmo tomaba a los frailes por bárbaros, más que a los escolásticos.
} 
los informantes su interpretación - de cuya respuesta difícil y vaga informa en los Preámbulos, como buen folklorista/antropólogo.

Creo que Castro no fue justo cuando señalaba la estrecha dependencia entre ambos textos introductorios, quitando luego importancia a las diferencias personales (como si fueran simplemente "defectos" del andaluz) y al hecho notable de que Mal Lara había descubierto la "filosofía vulgar" concreta de España - simplemente propuesta por Erasmo, como corolario de la homogeneidad entre las sentencias de sabios del mundoy había reunido sus refranes del pueblo presente y cercano. En ello no estaba empleando, como Montaigne por esas fechas en sus Ensayos, las noticias y textos clásicos al servicio de un debate moral europeo - como dice Castro, recordando al fin al modelo Montaigne, "la relatividad de los valores humanos, que dejaba amplio margen a la crítica y al juicio personal" (1925b: 592) - sino que estaba haciendo verdadero folklore y mostrando que la diferencia y sabiduría cultural que se halla en los textos clásicos podía encontrarse en la propia España.

Américo Castro, antiguo pensionado en Francia y émulo de las historias francesas de la literatura (historias sociológicas, que relacionaban la historia literaria con la política) echaba de menos un caso español a comparar, no encontrando merecedor siquiera al entonces recién fallecido Menéndez y Pelayo, y su Historia de las ideas Estéticas, 1891 (Castro 1925a: 162). Para analizar el caso de Mal Lara, en su estudio de Cervantes, no encuentra pertinente más que el texto de Menéndez y Pelayo Orígenes de la novela (1907 II: XL-XLI), que en realidad repite la misma idea de la Historia, antes despreciada, de 1891:

\begin{abstract}
Mal-Lara había pasado su vida enseñando letras clásicas ¿Quién se atreverá a decir que le apartasen de la comprensión y estimación de la ciencia popular en la cual tanto adelantó a su tiempo? Al contrario, de los antiguos aprendió el valor social e histórico de los proverbios o paremias. El mismo fenómeno observamos en otros grandes humanistas, en Erasmo ante todo, que abrió por primera vez esta riquísima vena, y con ella renovó el estudio de la antigüedad; en el comendador Hernán Núñez, infatigable colector de nuestros refranes, y en Rodrigo Caro, ilustrador de los juegos de los muchachos.
\end{abstract}

Castro, tras repetir esta cita de Menéndez y Pelayo, comenta: “Todo ello es evidente, pero algo externo, si al mismo tiempo no indicamos el sentido de ese culto por los refranes" (1925a: 191). Y lo mismo se le ocurre comentar ante estos mismos señalamientos del maestro por la paremiología de Mal Lara, en su texto coetáneo sobre éste:

revelaba, sin embargo, Menéndez y Pelayo no tener en cuenta el hondo problema que encierra el hecho de que los más doctos humanistas se ocuparan de re- 
franes, pues se limita a notar que Mal Lara, a imitación de Erasmo y Hernán Núñez, armonizó las letras clásicas con la ciencia popular [...] delicado problema histórico que supone ese popularismo de los espíritus más doctos en la ciencia de la antigüedad (1925b: 566).

La clave del asunto para Castro estaba en que Erasmo había mostrado el valor "cristiano" de la sabiduría clásica, y por ende, de una supuesta "Ciencia moral primitiva", derivada de la naturaleza. Yo estoy en que Américo Castro no había acertado más que don Marcelino, que no sólo lo trató en 1891 y 1907 sino, especialmente, en el discurso de contestación al de ingreso del folklorista Rodríguez Marín en la Academia Española:

El folk-lore, considerado como rama de las ciencias antropológicas y como parte esencialísima de la que Lazarus y Steinthal llamaron Völkerpsychologie (psicología de los pueblos), es moderno, en verdad, y su aparición no era posible sin el concurso de otras ciencias relativamente modernas también, como la mitología comparada y la historia de las instituciones. Pero gran parte de los elementos que entraron en la síntesis folk-lórica habían recibido una elaboración previa, más artística que científica. Las colecciones de cantos populares habían sido apreciadas por su valor estético, y algunas de ellas, sobre todo la de nuestros romances, formaban parte ya del patrimonio épico del género humano.

Grandes humanistas del siglo XvI, y Erasmo antes que ninguno, habían reconocido profundamente el valor de la sabiduría práctica contenida en los adagios y proverbios de los antiguos, y en torno de ellos había tejido el sabio de Rotterdam una especie de enciclopedia cuyo éxito superó al de todos sus libros. El triunfo de la paremiología clásica hizo volver los ojos a la paremiología vulgar, cuyo fondo era idéntico, y el impulso se sintió muy pronto en España, quizá la primera nación que se había cuidado de recoger sus proverbios, como lo prueba en el siglo xv la breve, pero inestimable colección del Marqués de Santillana. Eruditos y filólogos insignes de nuestro Renacimiento como Hernán Núñez y Juan de Mal Lara, no tuvieron a menos emplearse en tarea de tan humilde apariencia, y el segundo de ellos parece que presintió el futuro advenimiento de esta ciencia novísima, en aquel preámbulo de su Pbilosopbía Vulgar (título por sí mismo bastante significativo), en que con tanta claridad se discierne el carácter espontáneo y precientífico del saber del vulgo, y se da por infalible su certeza, y se marcan las principales condiciones de esta primera y rápida intuición del espíritu humano (Rodríguez Marín 1907: 77-78).

Yo no creo en absoluto, como Castro, que don Marcelino se haya quedado corto en su análisis y no haya explicado exactamente el problema principal, al contrario. Fue él quien lo señaló antes que nadie, debido precisamente a su propio clasicismo -opuesto a la moda germanista creciente, a que se adscribió primariamente el Centro de Estudios Históricos- y a su interés por los estudios clásicos en España. Y no sólo señaló el problema a analizar, sino que barruntó bastante de la solución: la 
paremiología popular que practican algunos humanistas es un resultado del clasicismo erasmista (que, junto con otros humanismos, rescata para el mundo cristiano el valor del mundo clásico, a pesar de su paganismo) y nace, no en un primer momento (cuando Erasmo descubre la vieja sabiduría pagana del pasado), sino en un segundo momento, cuando los humanistas aplican este descubrimiento al mundo presente, a los propios aldeanos o a los habitantes de nuevos mundos.

No es Erasmo -o su maestro Lorenzo Valla- quien descubre el folklore popular, quien entrevista a los aldeanos o incorpora relatos exóticos presentes, pero es siguiendo el modelo proveído por el mundo clásico, que sirve de ajeno desencadenante de la nueva consciencia acerca de la otredad cultural, como se descubre tal folklore. Creo que Castro ha adoptado una lógica difusionista para explicar la invención del folklore en Mal Lara (conectándolo a Erasmo, su "declarado" modelo), mientras que don Marcelino supo establecer una relación funcional entre clasicismo y filosofía popular, común a Erasmo y Mal Lara. Si bien le faltó avanzar en la diferencia entre ambos, en el peso del nacionalismo entre los humanistas de segunda generación que "vuelven los ojos a la paremiología popular" (que tan bien captó Maravall en 1966), no deja de ser por ello quien propuso el camino mejor. Menéndez y Pelayo inauguró los estudios sobre el erasmismo y sobre el clasicismo, y tanto Castro como Bataillon y Maravall eluden su nombre casi tanto como Mal Lara el de Erasmo, por cuestiones de corrección política, siempre coyuntural. Y también estuvo abierto a los estudios de folklore, para nuestra fortuna, gracias a su aprendizaje temprano con el romancista catalán Milá y Fontanals ("mi siempre venerado maestro", dirá en 1907, recordando su valorización de los Cantos populares de Rodríguez Marín), y a su pronta amistad con Rodríguez Marín y el gremio folklorista andaluz (editó los Días geniales, de Rodrigo Caro, y siguió con atención el folklorismo de Fernán Caballero).

\section{CONCLUSIÓN PROVISIONAL}

Pero, dejando a un lado la indudable presencia andaluza en el desarrollo histórico del folklore hispano (del Renacimiento de Mal Lara y R. Caro al romanticismo de F. Caballero y al positivismo de Machado), regresemos para terminar al nudo del problema aquí contemplado, el difícil parto del folklore hispano, gracias a la comadrona humanista. No sólo valen las consideraciones anteriores para unos pocos casos sino para la mayor parte de los folkloristas paremiólogos, como vimos que destacaban Menéndez Pelayo, Américo Castro, Bataillon y Maravall, y como han mostrado 
los estudiosos particulares de Santillana, Hernán Núñez, Páez de Castro, Mal Lara y Correas.

Una semblanza biográfica elemental de sus autores y obras debería reflejar que se trata en todos los casos de eminentes humanistas y profesores, ligados de forma protagonista a la universidad española (en particular a Salamanca, como destaca Hayes (1937), refiriéndose a Hernán Núñez, Páez de Castro, León de Castro — prologuista del Comendador, su maestro-, el propio Mal Lara, Cobarruvias y el maestro Correas). En este sentido, es curiosa su mayor adscripción a Salamanca que a Alcalá, sede del erasmismo. Mal Lara no quiso ir a Alcalá con sus nobles amigos sevillanos, cuando terminó en Salamanca, sino a Barcelona con un profesor educado en Italia y docente en Italia y Francia, Francisco de Escobar.

El caso del Comendador Griego se parece en su aristocratismo y brevedad de glosa a la del Marqués. Él no publicó la obra, largamente demorada, sino su discípulo León de Castro (el hebraísta y helenista que tanto hostigó a Fray Luis de León), que fue también quien puso unas palabras de presentación. Es importante -aunque ahora el espacio me falta para ello- destacar que lo importante de estos folkloristas, no era tanto la colección de los refranes como la glosa. Y la glosa no era, como para Erasmo, un cotejo de fuentes y casos grecolatinos, sino una búsqueda de ejemplos de uso (como harán los diccionarios para autorizar sus definiciones de términos, en particular el ilustrado de Autoridades, ya precedido por el de Cobarruvias). La cumbre de la glosa llegará con Juan de Mal Lara y Gonzalo Correas, dos profesores universitarios como el Comendador Griego. El primero reúne solamente 1.000 refranes, mientras que el segundo recoge 25.000 .

Ambos fueron eminentes profesores universitarios (de griego y latín el primero, y de griego, latín y hebreo el segundo) y destacados en sus respectivas ciudades de residencia, Sevilla y Salamanca. Ambos, también, conocidos por recoger los refranes de labios directos de los aldeanos, no de colecciones ajenas, como el Comendador Griego. Especialmente Mal Lara es un cabeza de fila del humanismo sevillano, con la misma categoría que su discípulo Fernando de Herrera. Allí están como tertulianos Francisco Pacheco, Pablo de Céspedes, Francisco de Medina, Barahona de Soto, Juan de la Cueva, Diego Girón, etc. Llegado a su tierra, tras diez años de estudios por España, inaugura una "escuela de gramática", que hace honrosamente las veces de Universidad o Estudios Generales. Traducirá textos griegos como los Apotegmas de Ausonio y otros clásicos, además de dominar las obras de Erasmo. Mal Lara competirá no solamente con el profesor salmantino el Comendador Griego, su maestro tardío, a quien quiere emular en sus glosas paremiológicas, sino que se escribirá 
con el Brocense, glosará a Erasmo y será invitado a componer sonetos en dos ocasiones muy solemnes para la ciudad: a la llegada de Felipe II y a la marcha del galeón de Juan de Austria para Lepanto. Son encargos oficiales, que demuestran su rango oficial como intelectual.

Pero su obra principal, que pasará a la posteridad y reclamará superaciones de parte de otros, será la Philosophia vulgar, de 1568. Como Erasmo, y en medio de debates con las fuerzas locales, irá a Madrid a lograr el permiso oficial de su edición, ofrecerla al rey y conseguir las máximas honras y ventas editoriales. Es, tal vez, el paremiólogo más afortunado, aunque su prematura muerte en 1572 -a los 47 años- interrumpa el proceso iniciado. Logra controlar esta edición, consigue una gran difusión de la obra, consagra una academia de sabios en Sevilla y son sus distinguidos cofrades y discípulos quienes continúan su labor. Creemos que los trabajos ecdóticos y de investigación del profesor M. Bernal (1982; 1996), unidos a la corte de mal-laristas insignes desde finales del s. XIX, coronan ese edificio privilegiado.

Lo que he querido en esta ocasión es sacarlo del altar local o nacional en que lo teníamos ubicado para, junto a los otros casos de humanistas paremiólogos, ofrecer a la Antropología una ocasión de reflexionar sobre la importancia de los precedentes internacionales y foráneos. Tal vez ha sido injusto que los estudios de folklore hayan estado minusvalorados por la Academia por su menor rango teórico o por sus cotos regionales, dado su complejo abolengo, pero algunos de los problemas suscitados en esta ocasión para servir esta meta común —contemplar las fronteras exteriores de una disciplina aparentemente local, o con interés privilegiado por lo local- deben tal vez esperar a su estudio pormenorizado.

\section{BIBLIOGRAFÍA EMPLEADA}

A) FUENTES PRIMARIAS

CORREAS, G. 1992. Vocabulario de refranes y frases proverbiales (1627). Edición de Louis Combet, revisada por Robert Jammes y Maïte Mir-Andreu. Madrid: Castalia.

Covarrubias Orozco, S. de [1611] 1979. Tesoro de la lengua castellana. Madrid: Turner. GARAY, B. de [1541]. Cartas en refranes. Toledo, 12 hojas.

Horozco, S. de (c. 1550). "Teatro universal. De los Proverbios, Adagios o comunmente llamados Refranes vulgares, que mas ordinariamente se usan en nra. España, Nuevamente copilados y glosados [...]" (Ms. en Bca. Nal. de Madrid, apud F. C. Hayes, 1937).

- 1915. Refranes glosados. Madrid: Real Academia Española.

- 1607. Proverbios y consejos que qualquier padre deue dar a su bijo... Salamanca: Antonia Ramírez. 
LÓPEZ DE MENDOZA, ÍÑIGO. (Marqués de Santillana). 1494. Los prouerbios de ... con su glosa... que fizo por mandado e ruego de nuestro señor el rey don Juan... Sevilla: Menardo Ungut y Stanislao Polono.

- 1508. Refranes que dicen las viejas bajo el fuego, e van ordenados por el ABC, recopilados por mandado del rey don Juan III de Castilla. Sevilla: Cromberger. Edición de Morel-Fatio, pseud. Urban Cronan, en Revue Hispanique, 1911, XXVV: 134-219.

MAL LARA, J. de 1568. Philosophia vulgar. Sevilla: Hernando Díaz.

- 1958. Edición, prólogo y notas de Juan de Mal Lara, Filosofía vulgar, por Antonio Vilanova. Barcelona, Selecciones bibliófilas, 2. ${ }^{\mathrm{a}}$ serie, 4 vols.

- 1996. Obras completas de Juan de Mal Lara. Vol. 1, La Philosophia vulgar. Edición y prólogo de Manuel Bernal Rodríguez. Madrid: Edit. Turner, Biblioteca Castro.

NúÑEZ, H. [1555] 2001. Refranes o proverbios en refranes, con sus glosas. Ed. crítica de Louis Combet, Madrid: Guillermo Blázquez, 2 vols.

Palmireno, L. 1560. Adagiorum Centuriae Quinq. Zaragoza: Pedro Banuz.

- 1569. El estudioso cortesano... añadido El Proverbiador... refranes de recreo, salud $y$ buena ciencia. Valencia.

ROTERDAM, D. E. de. 1500. Adagiorum Collectanea. París: Badius (sin Prolegómenos).

- 1508. Adagiorum Chiliades. Venezia: Aldo Manuzzio.

- 2000. Adagios del poder y de la guerra, y teoría del adagio. Valencia: Pre-textos, Colección Humaniora.

VAldÉs, J. de [c. 1535-6]. 1928. Diálogo de la Lengua. Madrid: Clásicos Castellanos, Edición de F. Montesinos.

VALLÉs, Mosén P. 1549. Libro de refranes copilado por el orden del ABC. En el qual se contienen quatro mil y trezientos refranes. El más copioso que hasta oy ha salido impresso. Zaragoza: Juana Milione (edición de M. García Moreno en 1917).

B) FUENTES SECUNDARIAS

ASENSIO, E. 1952. "El erasmismo y las corrientes espirituales afines (conversos, franciscanos, italianizantes)". Revista de Filología Española XXXVI: 31-99.

Bajtin, M. 1974. La cultura popular en la Edad Media y el Renacimiento. Barcelona: Barral Eds.

BATAILlON, M. [1937] 1979. Erasmo y España. Estudios sobre la bistoria espiritual del siglo XVI. México: Fondo de Cultura Económica.

- 1983. "Erasmo cuentista. Folklore e inventiva narrativa", en M. Bataillon (coord.), Erasmo y el erasmismo: 80-109. Madrid: Ed. Crítica.

Berkowitz, H. C. 1925. "The Quaderno de Refranes castellanos of Alfonso de Valdés". The Romanic Review XVI: 71-86.

BERNAL RoDRíguez, M. 1982. Cultura popular y bumanismo: Estudio de la Philosophia vulgar de Juan de Mal Lara. Madrid: Fundación Juan March, Serie Universitaria, 181.

BleCUA, A. 1979. "La litterature apothegmatique en Espagne", en A. Redondo (dir.) 1979: 120-132.

BURKE, P. 1991. La cultura popular en la Europa moderna. Madrid: Alianza Editorial. CASTRO, A. 1925. El pensamiento de Cervantes. Madrid: Centro de Estudios Históricos, Anexo de la Revista de Filología Española (facsimilar de 1987, Barcelona: Ed. Crítica, y dos ediciones anteriores de 1972 y 1980 en Barcelona: Ed. Noguer). 
- 1925b. "Juan de Mal Lara y su 'Filosofía vulgar'". Homenaje ofrecido a Menéndez Pidal. III: 563-592. Madrid: Ed. Hernando.

CEJADOR, J. [1915-22]. Historia de la Lengua y la Literatura castellana. Madrid: Gredos, 7 vols.

Chevalier, M. 1979. "Proverbes, contes folkloriques et historiettes traditionelles dans les oeuvres des humanistes espagnols paremiologues", en A. Redondo (dir.), 1979: 106-118.

Del PINo, F. 1992. "Acerca de las antropologías y las naciones de España". Antropología. Revista de pensamiento antropológico y estudios etnográficos 3: 112-119.

- 1996. "Clasicismo y génesis disciplinar antropológica: el caso de Julio Caro Baroja". RDTP LI: 303-330.

García Moreno, M. 1918. Catálogo paremiológico. Madrid: Librería S. Bernardo, 26.

GASPARINI, M. 1943. Cinquecento spagnolo. Juan de Mal Lara. Florencia: La Nuova Italia editrice.

GuICHOT Y SIERRA, A. 1922. Noticia bistórica del folklore. Sevilla: Hijos de G. Álvarez.

HAYES, E. C. 1937. "Collecting of proverbs in Spain before 1650". Hispania XX: 85-94.

LAPESA, R. 1957. La obra literaria del marqués de Santillana. Madrid: Ínsula.

Maravall, J. A. 1966. Antiguos y modernos. Madrid: Sociedad de Estudios y Publicaciones.

Melczer, W. 1979. "Juan de Mal Lara et l'école humaniste de Seville». En A. Redondo (dir.), 1979: 89-104.

MENÉndez y PELAYo, M. [1891] 1974. Historia de las Ideas Estéticas. Madrid: CSIC, 2 vols.

- [1907] 1961. Origenes de la novela. Madrid: CSIC, 4 vols.

Morreale, M. 1988. "Tradiciones populares y antigüedad clásica en el Tesoro de Cobarruvias. Sugerencias para su estudion. RDTP XLII: 437-439.

NADER, H. 1986. Los Mendoza y el Renacimiento español. Guadalajara: Diputación provincial.

NAvAsCuÉs, J. M. 1931. "El Foklore español. Boceto histórico", en F. Carreras Candi (dir.), Folklore y costumbres de España, 1: 1-164. Barcelona: A. Martín.

O'KANE, E. 1959. Refranes y frases proverbiales españolas de la Edad Media. Boletín de la Real Academia Española, anexo II, Madrid: Imp. Aguila Torre.

REDONDO, A. (dir.), 1979. L'Humanisme dans les lettres espagnoles. Etudes réunies et présentées par... París: Librairie Philosophique J. Vrin.

Rodríguez Marín, F. 1907. La figura literaria de Mateo Alemán. Discursos ante la R.A.E., por los excmos. señores D... y D. Marcelino M. y Pelayo, en la recepción pública del primero, el día 23 de octubre de... Sevilla, segunda edición.

Rowe, J. H. 1965. "The Renaissance Foundation of Anhropology". American Antbropologist 67: 1-19.

SÁNCHEz EsCRIBANO, F. 1933. Apuntes para una edición de la 'Philosopbia vulgar' de Juan de Mal Lara. Contribución al estudio del humanismo en España. Doctoral diss. Univ. of California, Berkeley.

- 1933. "Algunos aspectos de la elaboración de la 'Philosophia vulgar'". Revista de Filología Española XXII: 274-284.

- 1941. Juan de Mal Lara. Su vida y sus obras. Nueva York: Hispanic Institute.

- 1942. "Santillana y la colección de refranes". Hispanic Review X (2): 254-258.

- 1944. Los 'Adagia' de Erasmo en la 'Pbilosopbia vulgar' de Juan de Mal Lara. Nueva York: Hispanic Institute.

SBARBI, J. M. 1874. El Refranero General Español, parte recopilado y parte compuesto por... Madrid: Gómez Fuentenegro. 
- [1891] 1980. Monografía sobre los refranes, adagios y proverbios castellanos, y las obras o fragmentos que expresamente tratan de ellos en nuestra lengua. Madrid: Atlas.

Signes Codoñer, J.; C. CODOÑer y A. DOMingo (eds.). 2001. Biblioteca y epistolario de Hernán Núñez de Guzmán... Madrid: CSIC, Nova Roma, 14.

TRACY, J. D. 1980. “Against the 'Barbarians': the Young Erasmus and his Humanist Contemporaries". Sixteenth Century Journal XI (1): 3-22.

VelasCO, H. 1980. "Apuntes sobre los tratamientos históricos de un género de la tradición oral: los refranes", en Actas del Primer Congreso Español de Antropología, II: 157-171. Barcelona: Universidad de Barcelona.

YNDURAIN, D. 1994. Humanismo y Renacimiento en España. Madrid: Cátedra. 